1. Define what is meant by collective leadership;

2. Understand the importance of collective leadership within healthcare organisations;

3. Identify ways to get involved in projects involving collective leadership strategies for the future.

Results Junior clinicians are usually the ones able to identify many of the most pressing issues facing our health service today, due to their front line position. This means if equipped with the right tools, time, vision and opportunities they might also be able to resolve the same issues in the first instance; in turn improving system-wide safety and efficacy.

Discussion The King's Fund report 'Developing collective leadership for health care' states the importance of appropriate diversity of leaders in health care organisations.

The proposed masterclass workshop model, aims to help bring these concepts to life, through a mentoring-style session by sharing other speakers' real-life experiences. It further aims to demonstrate that leadership is not restricted to only some individuals and can be practised by all. In turn, increasing the confidence of early-career clinicians and empowering them to take on more responsibility for ensuring continuous high quality patient care regardless of their grade or position, through taking part in local or national initiatives.

\section{LEADING AND MANAGING CHANGE IN HEALTHCARE ORGANIZATIONS}

Savithiri Ratnapalan. University of Toronto, Hospital for Sick Children, Toronto, Canada

10.1136/leader-2019-FMLM.37

Aims To explore Emergency Department staffs' perceptions of factors influencing change and change management at a university teaching hospital in the United Kingdom.

Methods Grounded theory methodology was used to perform secondary analysis of 41 interview transcripts from participants consisting of 20 physicians, 13 nurses, two support workers and six managers involved in paediatric emergency care at the university teaching hospital.

Results Leadership was identified as one of the major factors influencing change and change management in the study. Four major themes related to leadership were identified. They were; the role of leaders and followers, authority and influence, power and empowerment and building relationships. Good and credible leaders and followers' trust in clinical leadership skills were discussed as important during changes. Leaders' influence with the team, empowering the team and building relationships both within the team and with other services in the hospital were stated to be important for successful change management. Leadership interactions that foster positive emotions motivate staff to implement or manage changes rather than the formal authority as a leader. Participants identified that clear communications and providing education associated with the change process as important leadership activities.

Conclusion Credible trusted leadership, encouraged positive emotions and reduced negative emotions to changes. Change management in healthcare organisation should not only guide leaders in traditional leadership functions but also prepare and equip them to support staff and build relationships to successfully adopt change and drive organizational success while ensuring the quality of care and patient safety are improved.
Leadership Lessons From Across The World

\section{IMPROVING EFFICIENCY OF MENTAL HEALTH CARE PROVIDED FOR PATIENTS WITH SEVERE MENTAL ILLNESS-SMIS (SCHIZOPHRENIA, SCHIZOAFFECTIVE DISORDER AND BIPOLAR AFFECTIVE DISORDER), A SUCCESS STORY FROM AMPARA, A RURAL REGION OF EASTERN SRI LANKA}

Hiranya Wijesundara. District General Hospital, Ampara, Sri Lanka

\subsection{6/leader-2019-FMLM.38}

Background In Ampara Health District, I provide services to a rural population of 273,286 population in $3810 \mathrm{~km} 2$ as sole psychiatrist. Multidisciplinary Area Mental Health Team (MDT), included multi-centred full-time staff(Medical Officers, Nursing Officers, Psychiatric Social Workers and assistant staff) and part-time staff(Occupational Therapist and Speech Therapist). Limited scope of services provided for patients with SMIs, was recognized by the team.

Aims To improve holistic bio-psycho-social management through MDT input. Areas chosen to intervene include data surveillance system, pharmacological treatment, psycho-social interventions, physical health and service delivery. Method: Patients and Carers feedback were gathered. Using Monthly Quality Circle meetings, existing situation was analysed. Interventions were designed with ideas of MDT to target each aspect of the problem. Team members were delegated to lead various interventions in the project from 2016-2018.

Results There were 641 patients with SMIs at central clinic in 2016. Outcome indicators for each intervention were developed and monitored. In an audit(165 patients), consultant review rate increased with reduction of rate of relapses. Monthly average number of general \& targeted psycho-social interventions increased, while stability of high-risk patients improved. Screening for physical comorbidities increased. To improve service delivery, additional peripheral clinic was initiated, and availability of common medications increased. In qualitative indicators, high patient satisfaction and increased community engagement in health promotional programs, were noted.

Conclusions Outcome indicators showed increased number of bio-psycho-social interventions and positive impact on outcome of patients. Service development through leading MDT is challenging but successful. This project won the Award for Mental Health Team of the Year at BMJ South Asia Awards for Health Care Excellence in 2018.

\section{Understanding Leadership Through Research}

\section{LEADERSHIP TRAINING AND EXPOSURE FOR JUNIOR DOCTORS IN A DEVON TEACHING HOSPITAL: A SURVEY}

Katharine A Edey*, Geraint A Phillips. Royal Devon and Exeter NHS Foundation Trust, UK

\subsection{6/leader-2019-FMLM.39}

Introduction Leadership and management (L\&M) experience is valued by junior doctors, although most feel unprepared to implement even local changes. ${ }^{1}$ Suggestions have been proposed for developing leadership in trainees, but without appraising juniors' current leadership opportunities. ${ }^{1-3}$ Thus, 